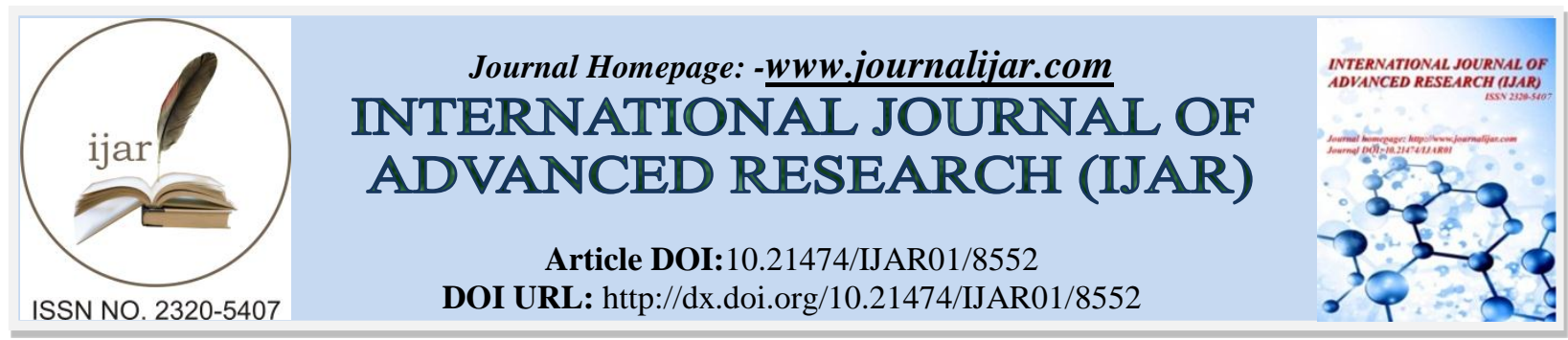

RESEARCH ARTICLE

\title{
ILEUM PERFORATION IN A YOUNG PATIENT WITH BEHÇET'S DISEASE.
}

Faisal El Mouhafid, Noureddine Njoumi,Youssra ouhamou, Aziz Fadili, Mountassir Moujahid, Abdelkader ihirchiou, Adbelmounim Aitali and Aziz Zentar.

Department of visceral surgery 2, Mohammed 5 Military teaching hospital, Ryad, Rabat, Morocco.

\section{Manuscript Info}

Manuscript History

Received: 14 December 2018

Final Accepted: 16 January 2019

Published: February 2019

\section{Abstract}

Intestinal Behcet's disease may cause serious complications. Massive hemorrhage, fistulisation and intestinal perforation are encountered complications in approximately $50 \%$ of patients suffering from intestinal Behcet's disease. The main sites of involvement are the terminal cecum and ileum. In patients with Behçet syndrome, CT is advocated for early detection of complications as well as for exclusion of other abdominal pathologic conditions but there is no specific exam. The report of histology in conjunction with the clinical history and the presence of oral ulcers, uveitis and suspected cutaneous lesions suggests the diagnosis. The optimal medical treatment of Behçet syndrome has not yet been well established. In rare cases surgery must be required to control the disease. We describe a case of ileal perforation with abscess in a 26-year-old female with Behcet's disease.

Copy Right, IJAR, 2019,. All rights reserved.

\section{Introduction:-}

Behçet syndrome is a chronic, recurring, systemic disorder characterized by the histopathologic finding of nonspecific vasculitis in multiple organs. The International Study Group for Behçet's Disease proposed new diagnostic criteria in 1990 [1]. These criteria require the presence of oral ulcers plus any two of the following: genital ulcers, typical eye lesions, typical skin lesions, or a positive result of a pathergy test. Behçet syndrome involves the gastrointestinal tract in 10-50\% of patients; such involvement results from vasculitis in the small vessels of the bowel wall, more frequently in the venules [2-3]. The main sites of involvement are the terminal ileum and cecum, but the upper gastrointestinal tract including the esophagus and, rarely, the stomach can be affected [4].

\section{Case report:}

A 26-year-old woman presented to the Emergency Department of our hospital complaining of abdominal pain, fever and vomiting, in the previous $24 \mathrm{~h}$. His medical history revealed that 11 years ago he was diagnosed with Behcet's Disease (BD). On examination, his vital signs were stable, but he presented an acute abdomen with fever. The laboratory results of the patient showed no anemia, an elevated leukocyte count and a high Creactive protein (Hb $13.3 \mathrm{~g} / \mathrm{dL}, \mathrm{WBC} 11500$, Plat 112000 . CRP $86 \mathrm{mg} / \mathrm{dl}$ ). We started the approach by asking an abdominal x-ray that showed a pneumoperitoneum. This way, an urgent CT scan revealed signs of pneumoperitoneum with abscess in the right iliac fossa (figure 1). An emergency laparotomy was performed for a suspected perforation in the GI tract. The right iliac fossa was filled with purulent fluid. During exploration, we found a perforation of the terminal ileum with stenosis (figure 2). We proceed to the resection of that segment of small bowel and a termino-terminal anastomosis. He was asymptomatic at the time of discharge from hospital. Histology revealed lacerations, areas of mucosal

Corresponding Author:-Faisal El mouhafid.

Address:- Department of visceral surgery 2, Mohammed 5 Military teaching hospital, Ryad, Rabat, Morocco. 
necrosis, and perforations, and granulocytic inflammation, focal proliferation of capillaries. These aspects in favour of BD.

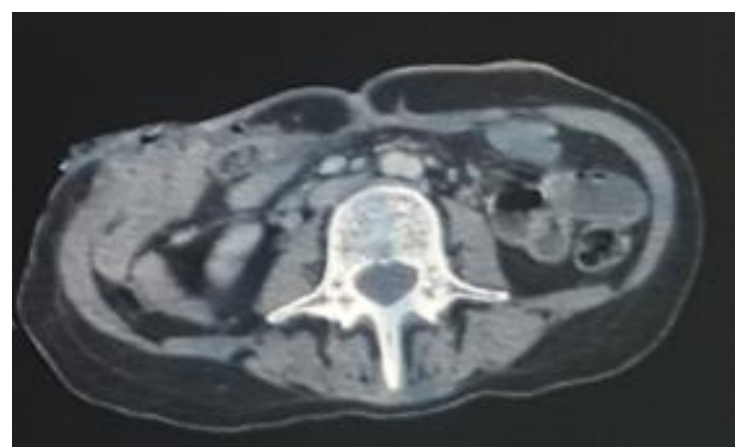

Figure 1:-abscess in the right iliac fossa

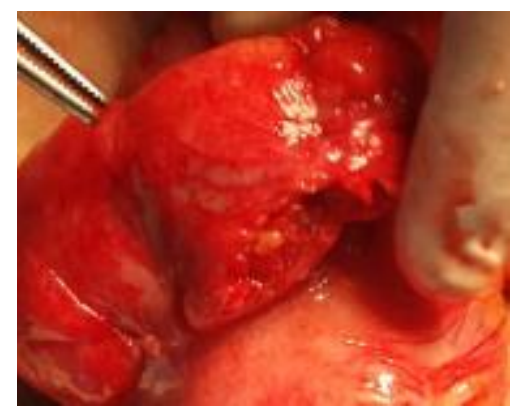

Figure 2:-perforation of the terminal ileum

\section{Discussion:-}

BD was first described in 1937 by the Turkish dermatologist, Hulus Behcet. Although seen worldwide, the highest prevalence is in Japan, the Middle East, and the Mediterranean region. It is uncommon in northern Europe and USA [5-6].The prevalence in Japan is 1 per 1000, in the Middle and Far East, 7 to 8 per 100,000, but 4 per 1,000,000 in the United States. The age at on set is usually between 20 and 30 years with a mean of 27 years, and men are more commonly affected, with $66 \%$ of case seen in males [5-7].

The etiology and pathogenesis are unknown, but theories include genetic factors, viral infection, environmental factors, and autoimmune mechanisms might play a role [8,9]. Also, there are some associations with human leukocyte antigens in Eastern countries [10]. In contrast to Reiter disease, in which the frequency of HLA-B27 is high, HLA-B5 and HLA-B51 are associated with Behçet syndrome. Although no organism is detectable, antistreptococcal antibodies have been found in some patients, and may be a more frequent history of streptococcal tonsillitis. Increased numbers of circulating immune complexes and elevated serum levels of tumor necrosis factor receptor, interferon gamma, and cytokines such as interleukin 1, interleukin 8, and antigens such as CD 8 and CD56 may be involved in the pathogenesis [5-11].

The diagnosis is made clinically. The Interna-tional Study Group for Behcet's Disease proposed a standardized set of criteria in 1990, including recurrent oral ulceration and at least two other criteria: recurrent genital lesions, characteristic eye lesions, characteristic skin lesions, or a positive pathergy test. Patients who have only two of these criteria are considered to have an incomplete form of BD. Herpes simplex infection must be ruled out in patients with recurrent oral or genital ulcers. Referral to an ophthalmologist to identify ocular involvement is necessary, and cutaneous lesions should be biopsied [5-11,12].

$\mathrm{BD}$ is considered a relapsing and remitting vasculitis of the small-to-medium sized vessels [7-12]. Erythema nodosum-like lesions of BD are characte-rized by panniculitis, usually with a lobular or mixed septal pattern, with variable numbers of neutrophils, lymphocytes, and histiocytes as well as variable numbers of necrotic adipocytes. Vasculitis is noted in most erythema nodosum-like lesions in BD [13]. 
Central nervous system manifestations include cerebellar ataxia,meningoencephalitis, benign intracranial hypertension, cerebrovascular thrombosis, and vasculitis.

Pulmonary arterial aneurysms, pulmonary hypertension, pulmonary embolism, pericarditis and myocardial infarction are infrequent. Some authors have reported intestinal BD to be associated with generalized myositis.

The main digestive tract symptoms are abdominal pain, fever, hematochezia, and diarrhea. Lesions may occur in any part of the digestive tract but are especially prominent in the ileocecal region. However, multiple esophageal and gastroduodenal ulcers may also be seen. The ulcers are discrete and relatively oval in shape rather than longitudinal; no cobblestone features are seen [5-11,14-15]. The appearance of central ringlike collections of barium superimposed on large nodular lesions in the terminal ileum has been reported to be a specific manifestation of intestinal BD [16].

Computed tomography (CT) has advantages in demonstrating bowel wall thickening and lesions in the extraluminal space. Therefore, in patients with Behçet syndrome, CT is advocated for early detection of complications as well as for exclusion of other abdominal pathologic conditions [17-18]. Furthermore, CT might allow prediction of the possibility of complications [17]. There is no specific exam. The report of histology in conjunction with the clinical history and the presence of oral ulcers, uveitis and suspected cutaneous lesions suggests the diagnosis. The differential diagnosis should include all the intestinal inflammatory diseases.

The optimal medical treatment of Bechet syndrome has not yet been well established. The natural history of exacerbation and remission makes evaluation of therapy difficult [19]. Corticosteroids are the mainstay of medical therapy in Behçet syndrome. Other medical treatments such as azathioprine, colchicine, dapsone, levamisole, thalidomide, and immunosuppressive therapies have been advocated $[18,20]$. For mucocutaneous lesions, steroids, colchicine and dapsone can be used. For more Severe mucocutaneous disease or systemic lesions, other immunosuppressants or interferon alfa can be added. There has also been a report of treating ileocecal ulceration using hyperbaric oxygen therapy in patient who was unresponsive to steroid therapy. The authors suggested that improved oxygenation and circulation to the mucosa may enhance fibroblast proliferation and lead to accelerated healing of the ulcer [21]. In rare cases surgery must be required to control the disease.

Kariv et al [22] reviewed 83 cases of systemic vasculitis presenting as a tumor-like lesion. The locations varied considerably and they found that surgery was sometimes performed unnecessarily because the diagnosis of vasculitis had not been considered.

\section{Conclusion:-}

Patients in whom medical therapy has been unsuccessful or who have extensive disease or complications such as perforation should be considered for surgery. This possibility should be included in the differential diagnosis of abdominal pain in such patient.

\section{References:-}

1. International Study Group for Behçet's Disease. Criteria for diagnosis of Behçet's disease. Lancet. 1990; 335: 1078- 1080. PubMed

2. Johnson WK, Beierle E, Ros PR. CT evaluation of the gastrointestinal tract in a patient with Behçet's syndrome. AJR Am J Roentgenol. 1994; 162: 349-350. PubMed | Google

3. Scholar

4. Lakhanpal S, Tani K, Lie JT, Katoh K, Ishigatsubo Y, Ohokubo T. Pathologic features of Behçet's syndrome: a review of Japanese autopsy registry data. Hum Pathol. 1985; 16: 790-

5. 795. PubMed |Google Scholar

6. Kasahara Y, Tanaka S, Nishino M, Umemura H, Shiraha S, Kuyama T. Intestinal involvement in Behçet's disease: review of 136 surgical cases in the Japanese literature. Dis Colon Rectum. 1981; 24:103-106.PubMed | Google Scholar

7. 5.Jayashri VG, Joseph LJ. Behcet's disease: epidemiology, diagnosis, patient evaluation, pathogenesis, clinical features, histopathologic features, prognosis, clinical course, treatment. In: Ruddy S, Harris ED, Sledge CB, eds. Textbook of Rheumatology. 6th ed. Philadelphia: W. B. Saunders Co., 1981: 1205-9. 
8. 6.Edwards L. Oral and genital ulcers and erision: oral and genital ulcers. In: Edwards L, ed. Dermatology in emergency care. Singapore: Churchill Livingstone Inc Press; 1997; 254-5.

9. 7.Ecker RD. Behcet's disease in an African American man .Am J Emerg Med 2000; 18: 118-9.

10. Parkin JV, Wight DGD. Behçet's disease and the alimentary tract. Postgrad Med J. 1975; 51: 260-264.PubMed | Google Scholar

11. Lehner T, Batchelor JR, Challacombe SJ, et al. An immunogenetic basis for the tissue involvement in Behçet's syndrome.Immunology. 1979; 37: 895- 900. PubMed | Google Scholar

12. O'Duffy JD. Behçet syndrome. N Engl J Med. 1990; 322: 326- 328. Google Scholar

13. 11.Scully C. Behcet's syndrome: aetiology, clinical features, prognosis, management.

14. In: R. H. Champion, J. L. Burton, D. A. Burns, SM. Breathnach, eds. Textbook of Dermatology 6th ed. Blackwell Science Lt Press;1998; 3072-3.

15. 12.Gonzalez-Gay MA. Systemic vasculitis in adults in Northwestern Spain, 1997-1998.

16. Medicine (Baltimore) 1999; 78: 292-308.

17. 13.Kim B. Histopathologic features of erythema nodosum-like lesions in Behcet's disease, a comparison with erythema nodosum focusing on the role of vasculitis. Am J Dermatopathol 2000; 22: 379-90.

18. 14.Glosemeyer R. Ulcerative esophagitis and colitis are rare manifestations of adamantiades-Behcet disease. Zeitschrift fur Gastroenterol 2001; 39: 167- 71.

19. 15.Levin MS. Small bowel ulcers associated with systemic disorders: Behcet's syndrome. In: Yamada T, Alpers DH, Lanine L, Owyang C, Powell DW, eds. Textbook of Gastroenterology. 3rd ed. Philadelphia. New York, Baltimore: Lippincott Williams \& Wilkins Press; 1999; 1744.

20. 16. Eisenberg RL. Ulcerative lesions of the colon: Behcet's syndrome. In: Eisenberg RL, ed. Gastrointestinal Radiology. A Pattern Approach. 3rd ed. Philadelphia. New York: Lippincott Raven Press, 1996; 634.

21. 17. Ha HK, Lee HJ, Yang SK, et al. Intestinal Behçet syndrome: CT features of patients with and patients without complications.Radiology. 1998; 209: 449-454. PubMed | Google Scholar

22. 18. Stringer DA, Cleghorn GJ, Durie PR, Daneman A, Hamilton JR. Behçet's syndrome involving the gastrointestinal tract: a diagnostic dilemma in childhood. Pediatr Radiol. 1986; 16(2):131-4. PubMed |Google Scholar

23. 19. Rosenberger A, Adler OB, Haim S. Radiological aspects of Behçet disease. Radiology. 1982; 144: 261 264.PubMed | Google Scholar

24. 20. Barnes CG et al. Behçet's syndrome. J R Soc Med. 1984; 77: 816-819. PubMed | Google Scholar

25. 21.Kume K, Hashiba T, Yoshikawa I, et al. Therapeutic experience of hyperbaric oxygenation in entero-Behcet syndrome. Am J Gastroenterol 2001; 96:1308-9.

26. 22.Kariv R. Systemic vasculitis presenting as a tumorlike lesion. Medicine (Baltimore) 2000; 79: 349-59. 